\title{
zeste, a nonessential gene, potently activates Ultrabithorax transcription in the Drosophila embryo
}

\author{
Jeffrey D. Laney and Mark D. Biggin \\ Department of Molecular Biophysics and Biochemistry, Yale University, New Haven, Connecticut 06511 USA
}

\begin{abstract}
The GAGA, NTF-1, and zeste proteins have been purified previously from Drosophila embryo extracts and shown to activate the Ultrabithorax $(U b x)$ promoter in vitro. Here, differently mutated $U b x$ promoter constructs containing binding sites for none, one, or all three of these transcription factors have been introduced into Drosophila by P-element transformation. Binding sites for each factor activate dramatically different patterns of transcription. In zeste mutant embryos, the activation by zeste protein-binding sites is essentially abolished. These genetic data, when considered with our earlier biochemical experiments, demonstrate that zeste directly and potently activates $\mathrm{Ubx}$ transcription in vivo. Surprisingly, previous genetic experiments indicate that zeste is a nonessential gene shown only to act in a dispensable regulatory process termed transvection. In our transgenic experiments, zeste is not activating transcription by transvection. We propose that the function of zeste in Drosophila is much broader than assumed previously, and that it is a member of a redundant system of transcription factors that regulate and maintain the expression of $U b x$ and other Drosophila genes.
\end{abstract}

[Key Words: zeste; Drosophila; Ultrabithorax; transcription nonessential gene; redundancy]

Received April 1, 1992; revised version accepted April 30, 1992.

The generation of complex spatial and temporal patterns of transcription in eukaryotes involves the coordinated interaction of multiple factors bound to proximal promoter and distant enhancer/silencer elements (for review, see Biggin and Tjian 1989a; Herskowitz 1989; Johnson and McKnight 1989; Mitchell and Tjian 1989; Guarente and Bermingham-McDonogh 1992). To understand the detailed mechanisms of transcriptional regulation during development, we are investigating the control of the Drosophila homeotic gene Ultrabithorax (Ubx).

Genetic and molecular analyses have identified several distant cis-acting elements that each regulate specific aspects of $U b x$ expression (Lewis 1978; Bender et al. 1983; Beachy et al. 1985; White and Wilcox 1985; Bienz et al. 1988; Simon et al. 1990; Irvine et al. 1991; Müller and Bienz 1991; Qian et al. 1991). The original genetic lesions mapped to very large regions in the $U b x$ promoter. Recently, however, it has been shown that a few short DNA elements within these sequences are sufficient to generate a pattern of expression closely resembling that of the endogenous $U b x$ gene (Müller and Bienz 1991). When these short elements are linked to a $U b x$ cDNA, the embryonic and larval lethality of $\mathrm{Ubx}^{-}$homozygotes can be rescued (Müller and Bienz 1991; Castelli-Gair et al. 1992). It is thus possible to analyze mutations in single transcription factor-binding sites in the context of normal $U b x$ expression.
Genetic experiments have also defined many transregulators of $U b x$ (e.g., Lewis 1978; Ingham and Whittle 1980; Struhl and Akam 1985; Struhl and White 1985; Ingham and Martinez-Arias 1986; White and Lehmann 1986; Bienz and Tremml 1988; Martinez-Arias and White 1988; Irish et al. 1989|. This detailed research suggests that $U b x$ expression is initiated in early embryogenesis by numerous spatially restricted activators and repressors. The resulting pattern of expression is then sustained throughout development by a second group of maintenance proteins. Various molecular and biochemical approaches have been employed to determine which of these regulators interact directly with $U b x$ promoter elements and also to identify other transcriptional regulators of $U b x$ (Beachy et al. 1988; Biggin and Tjian 1988, 1989b; Biggin et al. 1988; Krasnow et al. 1989; Müller et al. 1989; Winslow et al. 1989; Zink and Paro 1989; Qian et al. 1991; Zhang et al. 1991). In this paper we examine the roles of three proteins (GAGA, NTF-1, and zeste) originally identified as activators of $U b x$ by studies employing biochemical fractionation, DNA-binding assays, and in vitro transcription reactions (Biggin and Tjian 1988; Biggin et al. 1988; Dynlacht et al. 1989; M.D. Biggin, U. Heberlein, and R. Tjian, unpubl.).

Purification of GAGA, NTF-1, and zeste proteins from embryo extracts revealed that they each bind to distinct elements clustered just upstream of the $U b x$ mRNA start site (for review, see Biggin and Tjian 1989a). GAGA 
and zeste proteins are uniformly expressed in most cells of the embryo (Pirrotta et al. 1988; S. Bickel and V. Pirrotta; W. Soeller and T. Kornberg; both unpubl.), whereas the expression of NTF-1 is restricted to a subset of cells in the ectoderm (Bray et al. 1989; Dynlacht et al. 1989). The ubiquitous expression of GAGA and zeste raised the question of whether these proteins act to simply raise the level of transcription in all cells or whether they regulate specific patterns of transcription by combinatorial interaction with other proteins. Another question that remains unanswered by the biochemical experiments concerns an apparent conflict between the in vitro transcription data and a genetic analysis of the zeste locus. Although zeste is known to act on $U b x$ through a nonessential process termed transvection, flies that completely lack zeste are fertile, essentially wild type in appearance, and express the endogenous $U b x$ gene normally (Goldberg et al. 1989). These genetic data could suggest that $U b x$ is not significantly regulated by zeste and that zeste protein does not act as a transcription factor in Drosophila. Alternatively, zeste could be a transcription factor whose function redundantly overlaps with that of other factors. To resolve this issue and to determine the role of GAGA, NTF-1, and zeste in the regulation of $U b x$ transcription, we have examined the expression of different mutant $U b x$ promoter-lacZ reporter genes in the Drosophila embryo.

\section{Results}

The expression pattern of $U b x$ is directed by at least five distant regulatory regions and a single short promoter element near the start site of transcription (Fig. 1, top). The function of the distant elements has been studied by transgenic experiments in which different $U b x$ promoter-lacZ reporter gene constructs have been integrated into the Drosophila genome. The proximal promoter alone (nucleotides -200 to +968 ) generates only very weak expression in a pattern that bears no resemblance to that of the endogenous $U b x$ gene (Bienz et al. 1988). However, when each distant element is linked to the proximal promoter, high levels of expression are generated and each element activates different subsets of the $U b x$ expression pattern (Bienz et al. 1988; Simon et al. 1990; Müller and Bienz 1991; Qian et al. 1991). By including combinations of distant regulatory elements in promoter constructs, a pattern closely resembling that of wild-type $U b x$ expression can be generated (Müller and Bienz 1991). For example, inserting the BXD element upstream of the proximal promoter results in a segmentally repeated pattern of expression in the abdomen like that of endogenous $U b x$. However, the BXD element activates expression from head to tail (parasegments 2-14). When both the ABX silencer element and the BXD element are included with the proximal promoter, the BXD pattern is repressed in parasegments 2-4 and 14 (Müller and Bienz 1991). Thus, the resulting pattern of expression is restricted along the anteroposterior axis to the same region of the embryo as endogenous $U b x$ (parasegments 5-13).

Because transgenes containing the $\mathrm{ABX}, \mathrm{BXD}$, and proximal promoter elements are expressed similarly to the endogenous $U b x$ gene, we have adopted this assay to study the function of the GAGA, NTF-1, and zeste binding sites in the proximal promoter. Initially, a $U b x-l a c Z$ fusion gene containing these regulatory elements (construct U $\beta$; Fig. 2) was introduced into Drosophila by P-element transformation (Spradling 1986). The resulting lacZ expression pattern was analyzed by histochemical staining of whole embryos for $\beta$-galactosidase activity. All of the individual transformant lines give the same patterns of $l a c Z$ expression observed by Müller and Bienz (1991; described above). Expression in six of seven $\mathrm{U} \beta$ transformants is largely restricted to the same region of the embryo as endogenous $U b x$ (parasegments 5-13) (Fig. 3A), whereas expression in the remaining transformed line extends more anteriorly into the labial segment (parasegment 2) (Fig. 3 and data not shown). This expression in the labial segment can be explained by a failure of the $\mathrm{ABX}$ silencer element to repress the $\mathrm{BXD}$ pattern when constructs are inserted in some chromosomal locations (Müller and Bienz 1991). It should be
Figure 1. Regulatory elements of Ultrabithorax. (Top) The positions of the five known distant enhancer/silencer elements (PBX, BXD, VM, BX, and ABX) and the proximal promoter $(\mathrm{P})$ of $U b x$ are diagramed (Bienz et al. 1988; Simon et al. 1990; Müller and Bienz 1991; Qian et al. 1991; Zhang et al. 1991). The scale is in kilobases $(\mathrm{kb})$, and the start site of transcription is designated +1 . The exons of the longest $U b x$ mRNA are diagramed as black boxes, and the introns as stippled lines. (Bottom) Summary of the characterized transcription factors binding to a 280 bp region surrounding the start site of $U b x$ transcription (for review, see Biggin and Tjian 1989a) (G) GAGA; (NT) NTF-1; (Z) zeste; (HD) homeo domain proteins.

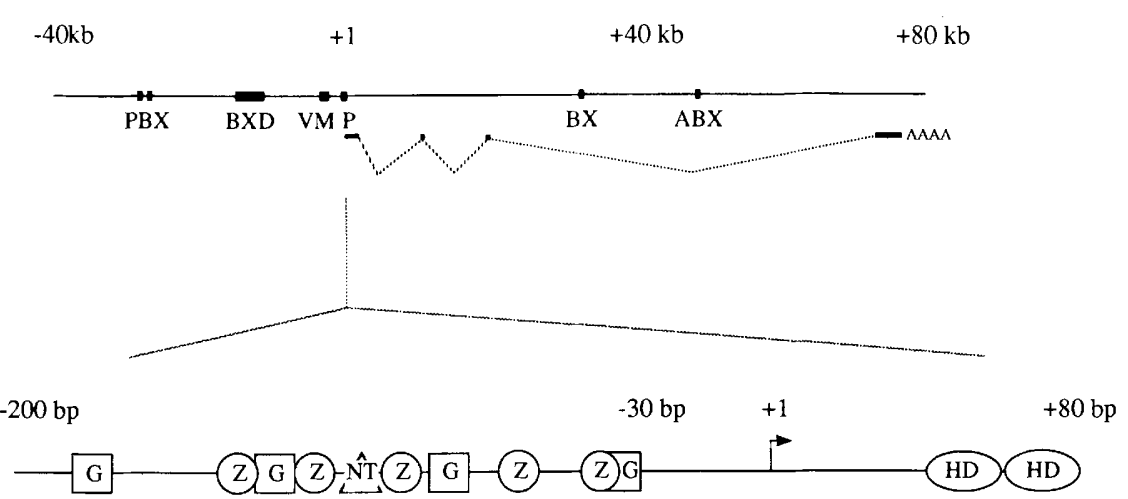


stressed that all other aspects of the Uß expression pattern are constant between every transformant line.

DNase I footprinting studies show that the GAGA, NTF-1, and zeste transcription factors bind to a cluster of sites upstream of the $U b x$ mRNA start site between nucleotides -31 and -200 (Fig. 1, bottom). To understand the function of these three proteins, their binding sites were removed by making an internal deletion of nucleotides -31 to -200 , without altering the remainder of the proximal or distant regulatory elements $(U \beta \Delta-200 /$ -31 ; Fig. 2). In comparison to the $U \beta$ parent construct described above, the pattern of expression generated by the U $\beta-200 /-31$ transgene is altered dramatically. Most strikingly, removing the proximal factor-binding sites completely abolishes fusion gene expression in the lateral epidermis of all $U \beta \Delta-200 /-31$ lines and results in transgene expression being exclusively localized to the ventral nerve cord (Fig. 3B,C). The level of transcription is also reduced dramatically, as $U \beta \Delta-200 /-31$ transformants must be stained 50 times longer than $U \beta$ constructs to achieve similar staining intensity in the nerve cord. Furthermore, none of the individual $U \beta$
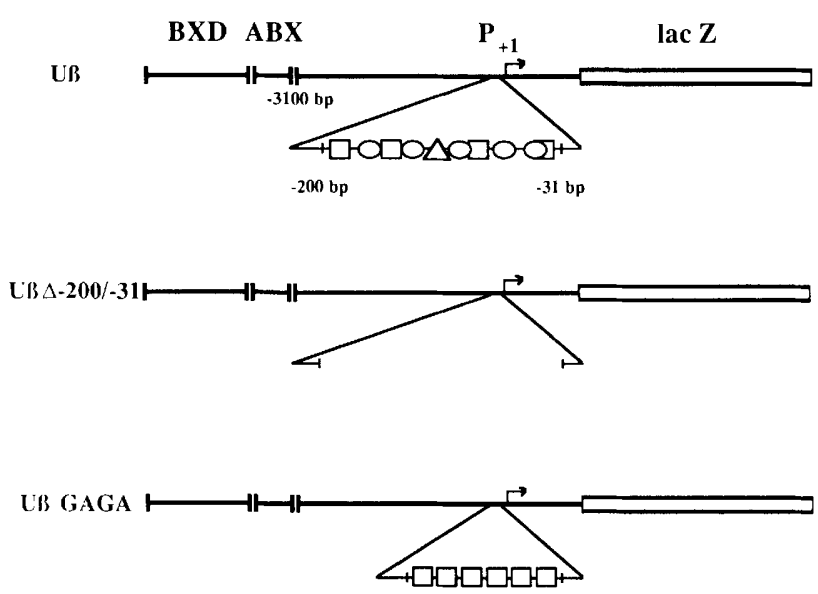

UB NTF-1
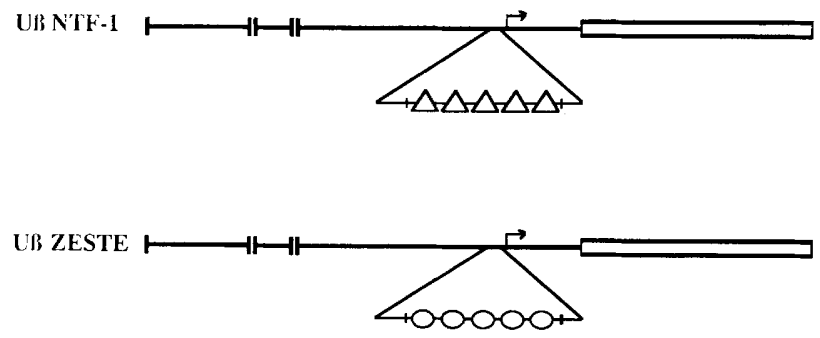

Figure 2. Diagrams of $U b x$ promoter-lacZ reporter fusion gene constructs. All constructs contain the $\mathrm{ABX}(0.6 \mathrm{~kb})$ and BXD $(1.6 \mathrm{~kb})$ distant regulatory elements fused upstream of the $4.1-\mathrm{kb}$ proximal promoter fragment of $U b x$. The $U \beta$ construct contains the natural $U b x$ proximal promoter sequence. $U \beta$ $\Delta-200 /-31$ lacks sequences from -31 bp to -200 bp in the proximal promoter. U $\beta$ GAGA, U $\beta$ NTF-1, and U $\beta$ ZESTE have six, five, and five binding sites for the GAGA, NTF-1, and zeste proteins, respectively. These sites are inserted at the $\Delta-200$ / -31 deletion site (for details, see Materials and methods.).

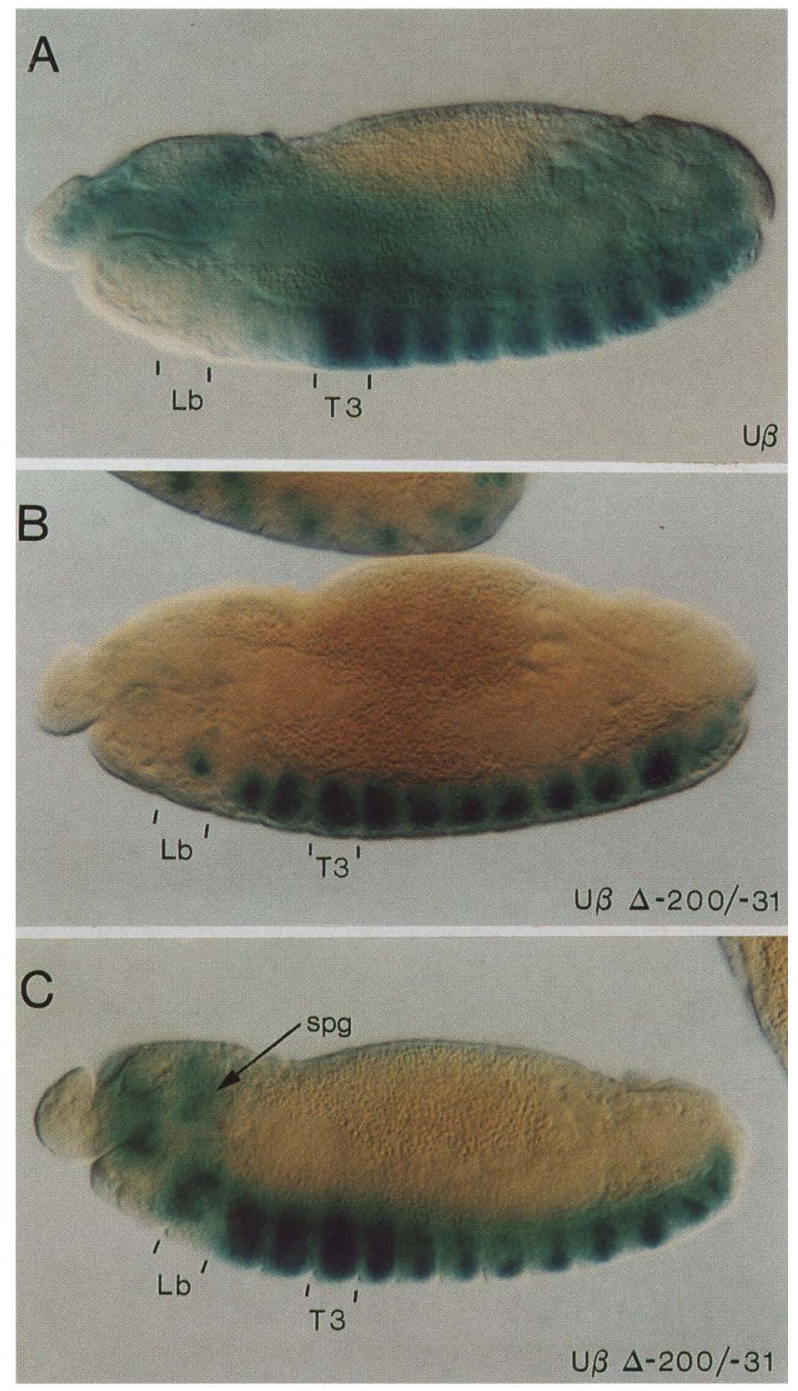

Figure 3. Expression patterns of the $U \beta$ and $U \beta \Delta-200 /-31$ constructs. Each panel is a lateral view of a stage- 13 transgenic embryo stained for $\beta$-galactosidase activity (stages according to Campos-Ortega and Hartenstein 1985). (A) The U $\beta$ transgene exhibits an anterior boundary of strong expression at the third thoracic segment (T3). Repression by the ABX silencer element causes greatly reduced expression anterior of this position and is observed in six of seven transformed lines. The other $U \beta$ line is not silenced as it is expressed at similar intensity in the labial segment and third thoracic segment (not shown). (B) All U $\beta$ $\Delta-200 /-31$ transgenes lack expression in the epidermis and show the same segmentally repeated pattern of expression in the ventral nerve cord. Four of eight transformant lines express $\beta$-galactosidase in the nerve cord as far anteriorly as the labial neuromere $(\mathrm{Lb})$. Another line is expressed as far anteriorly as the first thoracic neuromere (not shown). (C) The other three U $\beta$ $\Delta-200 /-31$ transformant lines are expressed farther anteriorly into the gnathal neuromeres and supraesophogeal ganglia (spg). $\mathrm{U} \beta$ transgenic embryos were stained for $0.5 \mathrm{hr}$; $\mathrm{U} \beta \Delta-200 /-31$ embryos were stained for $24 \mathrm{hr}$ to obtain similar levels of staining intensity.

$\Delta-200 /-31$ transformants appear to be repressed by the $\mathrm{ABX}$ silencer element, as they all strongly express the 
reporter gene anterior to the third thoracic neuromere (Fig. 3B); some lines express $\beta$-galactosidase as far anterior as the supraesophogeal ganglia (Fig. $3 \mathrm{C}$ ). Together, these results suggest that GAGA, NTF-1, and/or zeste regulate specific aspects of the spatial pattern of $U b x$ expression.

Despite the dramatic and consistent differences in their epidermal pattern of expression, both the $U \beta$ and U $\beta \Delta-200 /-31$ transgenes have a similar segmentally repeated expression pattern in the ventral nerve cord. Ventral views show that the same four groups of cells stain prominently in the thoracic and abdominal neuromeres of all $U \beta$ and $U \beta \Delta-200 /-31$ transformants (data not shown). Furthermore, the levels of reporter gene expression from both transgenes are reduced posterior to the first abdominal segment (Fig. 3). This probably reflects repression of both transgenes by the posterior homeotic genes abdominal-A and Abdominal-B (Struhl and White 1985; B. Christen and M. Bienz, unpubl.). Thus, the pattern generated by the U $\beta \Delta-200 /-31$ construct constitutes a subpattern of $U \beta$ expression.

\section{Binding sites for GAGA, NTF-1, and zeste give rise to different patterns of transgene expression}

To determine the role of GAGA, NTF-1, and zeste in regulating $U b x$ expression, we sought to design different constructs whose proximal promoters would be bound by only one of these transcription factors while retaining the other regulatory elements present in the $U \beta$ parent construct. Three different transgenes were constructed that contain multiple binding sites for GAGA, NTF-1, or zeste inserted into the $\mathrm{U} \beta \Delta-200 /-31$ construct at the site of the internal deletion (U $\beta$ GAGA, U $\beta$ NTF-1, and U $\beta$ ZESTE; Fig. 2). The individual binding sites used in these constructs have been characterized extensively: Purification of these proteins to apparent homogeneity from Drosophila embryo extracts has demonstrated that these are the only proteins that can be detected binding to these short DNA sequences (Biggin and Tiian 1988; Biggin et al. 1988; Dynlacht et al. 1989; M.D. Biggin, U. Heberlein, and R. Tijian, unpubl.). In addition, GAGA and zeste do not show any homology to the DNA-binding domains of other characterized transcription factors (Pirrotta et al. 1987; Mansukhani et al. 1988; W. Soeller and T. Kornberg, unpubl.), whereas very limited homology has been noted between NTF-1 and helix-loop-helix regulatory proteins (Bray et al. 1989; Dynlacht et al. 1989|; this suggests that these three proteins do not belong to families of transcription factors that bind promiscuously to the same DNA sites. These different data, however, cannot completely exclude the possibility that other proteins could recognize these elements, particularly in a small number of cells in the embryo.

The ability of binding sites for each of the three factors to influence transcription in the embryo has been assessed by comparing the expression patterns of $U \beta$ GAGA, U $\beta$ NTF-1, and U $\beta$ ZESTE to that of the U $\beta$ $\Delta-200 /-31$ construct. U $\beta \Delta-200 /-31$ transformants, which lack proximal factor binding sites, express $\beta$-ga- lactosidase exclusively in the ventral nerve cord /Fig. 4A). In contrast, transgenes containing binding sites for either the GAGA, zeste, or NTF-1 proteins are expressed in both the lateral epidermis and ventral nerve cord /cf. Fig. 4C, D, and E with A). The patterns and levels of epidermal expression differ dramatically between the $U \beta$ GAGA, U $\beta$ NTF- 1 , and U $\beta$ ZESTE constructs but are consistent between different transformed lines of the same transgene.

Close inspection of the pattern in the epidermis of U $\beta$ GAGA embryos reveals weak $\beta$-galactosidase expression around the furrow between the second and third thoracic segments. In addition, narrow stripes of faint expression in the dorsolateral epidermis are evident throughout the thorax and abdomen (Fig. 4C). U $\beta$ NTF-1 transgenes are expressed diffusely throughout the head epidermis and in stripes along the segmental furrows of the thorax and abdomen (Fig. 4E). Unlike the narrow stripes of expression in the epidermis of these two constructs, the reporter gene of U $\beta$ ZESTE is expressed in wide blocks closely resembling expression from the $U \beta$ construct (cf. Fig. $4 \mathrm{D}$ with B) and the endogenous $U b x$ gene in the abdomen. This segmentally repeated pattern is activated by the BXD element (Müller and Bienz 1991), which suggests that zeste protein-binding sites and the BXD regulatory element act in concert to generate this pattern of expression. NTF-1 and zeste protein-binding sites cause particularly strong activation, as embryos containing $U \beta$ NTF- 1 and U $\beta$ ZESTE transgenes are only stained onetenth the time of embryos carrying U $\beta$ GAGA and $U \beta$ $\Delta-200 /-31$ constructs. The observation that binding sites for each factor activate different patterns of transcription suggests that the proteins that bind these sites are not simply general activators but, instead, have specific roles in controlling different aspects of $U b x$ expression.

The presence of GAGA, NTF-1, and zeste proteinbinding sites in the proximal promoter may also alter the degree of transgene expression in the anterior of the embryo, possibly by affecting the silencing activity of the ABX element. All U $\Delta-200 /-31$ transformant lines do not appear to be silenced by the $\mathrm{ABX}$ element. In contrast, some $(40 \%)$ of the U $\beta$ GAGA transformants exhibit partial silencing of expression anterior to the third thoracic segment (Fig. 4C). Some U $\beta$ ZESTE lines display very weak silencing in the anterior segments, whereas little, if any, repression of the BXD pattern is observed in U $\beta$ NTF- 1 (Fig. 4E) lines. Silencing of the BXD pattern by the ABX element is dependent on the Polycomb gene (Müller and Bienz 1991). Thus, the proximal promoter factors may play a role in mediating repression by Poly$c o m b$. However, the variability of anterior expression between different transformant lines of the same construct prevents a decisive conclusion.

\section{The Ubx promoter is activated by zeste in the embryo}

Flies containing overlapping chromosomal deficiencies that lack the entire zeste locus are fertile and do not exhibit homeotic transformations (Goldberg et al. 1989). 

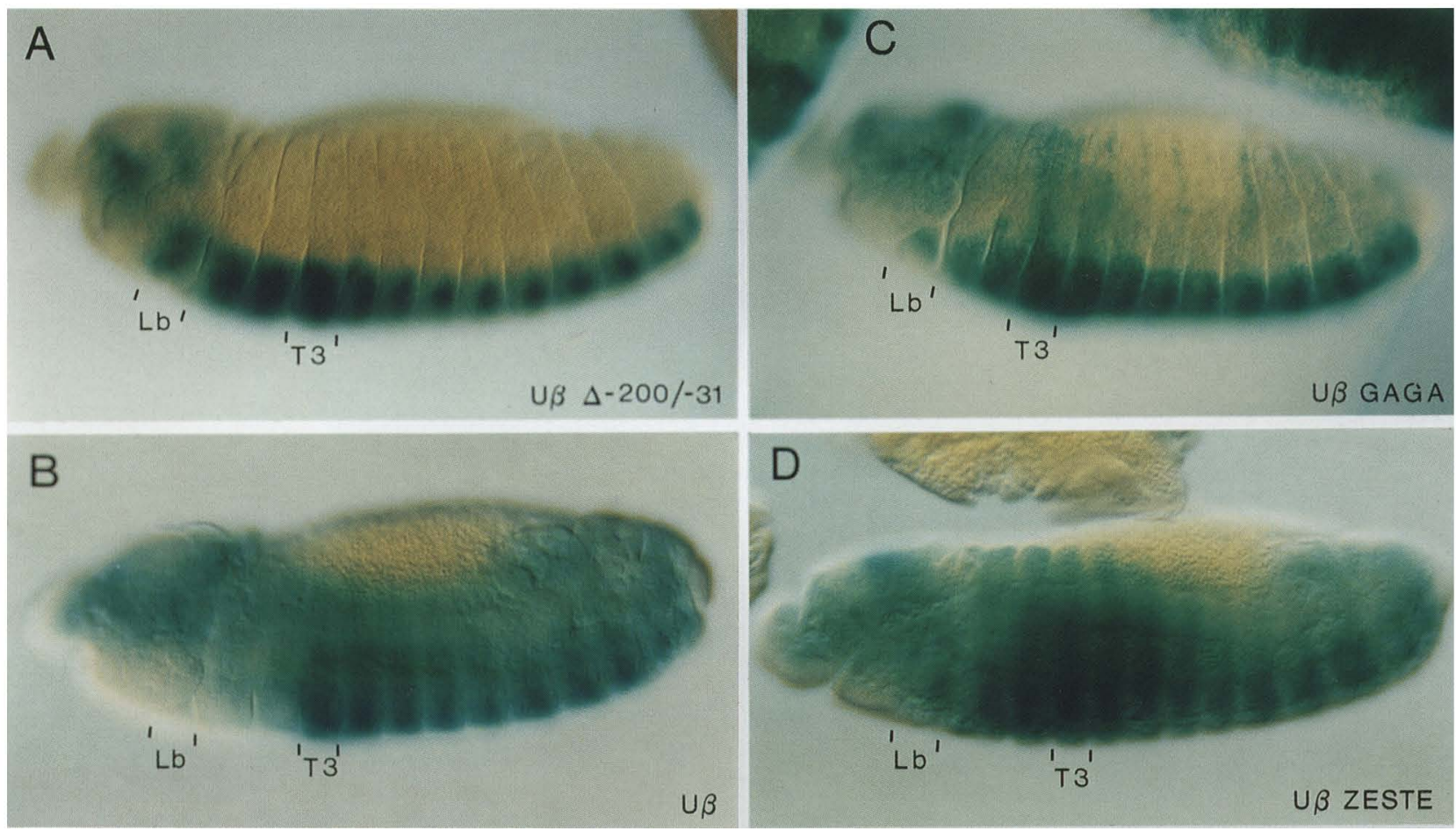

Figure 4. Proximal factor binding sites activate different patterns of expression. Reporter gene expression in $U \beta \Delta-200 /-31$ $(A), \mathrm{U} \beta(B), \mathrm{U} \beta$ GAGA $(C), \mathrm{U} \beta$ ZESTE $(D)$, and U $\beta$ NTF-1 $(E)$ transformant embryos has been localized by $\beta$-galactosidase activity staining. Stage-13 embryos were photographed at a higher plane of focus than in Fig. 3 to highlight expression in the lateral epidermis. The number of independent lines and staining times for each substitution construct are as follows: (U $\beta$ GAGA) 5 lines, $18 \mathrm{hr}$; (U $\beta$ NTF-1) 6 lines, 2 hr; (U $\beta$ ZESTE) 10 lines, $1.5 \mathrm{hr}$. The patterns of expression are essentially the same for all lines of each substitution construct, except that $40 \%$ of U $\beta$ GAGA transformants have reduced expression anterior of the third thoracic segment.

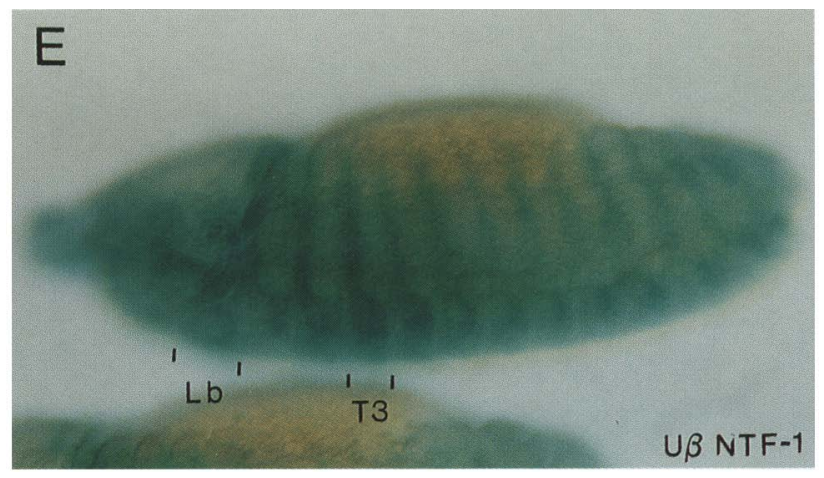

The fact that zeste is a nonessential gene could indicate that zeste has no significant effect on the endogenous $U b x$ gene. In contrast, we show that zeste protein-binding sites potently activate the transcription of $U b x$ promoter constructs in the embryo (Fig. 4D). Also, it has been shown previously that purified zeste protein directly activates $U b x$ transcription in vitro (Biggin et al. 1988). Because of these apparently conflicting data, we have sought to provide further evidence that zeste can activate $U b x$ transcription in vivo. Expression from transgenes containing or lacking zeste protein-binding sites has been examined in a strain carrying the $z^{v 77 h}$ allele of zeste. This allele contains a 314-bp deletion that removes mRNA leader sequences as well as the AUG initiation codon. From sequence analysis of zeste, it is predicted that a truncated polypeptide lacking the DNA. binding domain is produced by this allele (Pirrotta et al. 1987; Goldberg et al. 1989). This, together with the genetic behavior of $z^{v 77 h}$ (Green 1984), suggests that this allele is a true null or severe loss-of-function mutation.

Multiple independently transformed chromosomes carrying the U $\beta$ ZESTE construct were crossed into this mutant strain. Figure $5, A$ and $B$, shows the comparison of the U $\beta$ ZESTE expression pattern in a wild-type and $z^{v 77 h}$ genetic background. As described earlier, the lateral epidermis and nerve cord of U $\beta$ ZESTE transgenic embryos stain strongly for reporter gene activity in a pattern closely resembling the BXD pattern (Fig. 5A). Crossing this transgene into the $z^{v 77 h}$ mutant background virtually abolishes reporter gene expression in the epidermis, but expression in the nerve cord is only reduced $\sim 10$-fold (Fig. $5 B$ ). This is the expected result if zeste protein acts directly on this transgene, because zeste protein-binding sites potently activate transcription in the epidermis and only moderately affect expression in the nerve cord. Faint $\beta$-galactosidase staining remains in a few epidermal cells of some embryos. This may reflect binding of another protein to the zeste-binding sites in some cells of the embryo or could indicate that some residual zeste activity is produced by this allele. 

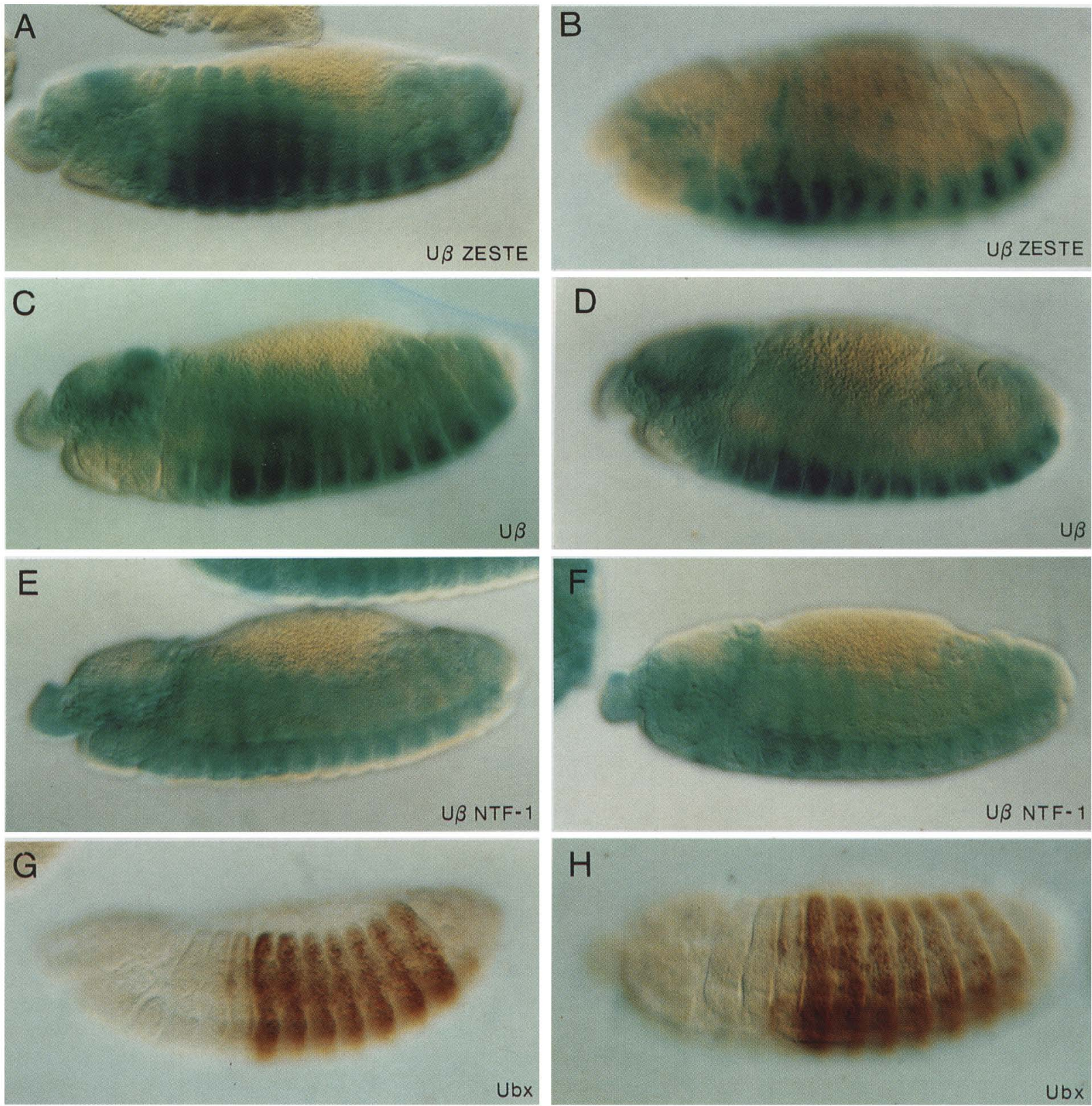

Figure 5. Ubx constructs containing zeste protein-binding sites are dependent on zeste gene function. Expression of various $U b x-$ lac $Z$ transgenes has been visualized by $\beta$-galactosidase staining in wild-type $(A, C, E)$ and $z^{v 77 h}(B, D, F)$ embryos. U $\beta$ ZESTE $(A, B), \mathrm{U} \beta$ $(C, D)$, and U $\beta$ NTF-1 $(E, F)$ transgenic embryos are shown. The same transformant line of each construct is presented in the different genetic backgrounds. Relative to wild-type, U $\beta$ ZESTE and U $\beta$ constructs in the $z^{v 77 h}$ background are stained 10 and 30 times longer, respectively. U $\beta$ NTF-l constructs are stained for equivalent times in both genetic backgrounds. Three U $\beta$ ZESTE lines, two U $\beta$ lines, and one U $\beta$ NTF-1 line have been examined with the same result. The expression of the endogenous Ubx proteins is detected by immunohistochemistry in wild-type $(G)$ and zeste mutant $(H)$ embryos. Staining times for each genetic background are equivalent.

The parent $\mathrm{U} \beta$ construct also contains zeste proteinbinding sites. Because these sites activate transcription more potently than GAGA- or NTF-1-binding sites (Fig. 4), expression from the $U \beta$ transgene should also be reduced in a $z^{v 77 h}$ mutant background. Strikingly, the high-level $\beta$-galactosidase expression in the epidermis is lost when $z^{v 77 h}$ embryos carry the U $\beta$ transgene (cf. Fig. $5 \mathrm{C}$ with $\mathrm{D}$ ). The weak residual expression in the epidermis is presumably the result of activation of this construct by the GAGA and/or NTF-1 transcription factors 
still present in this genetic background or could result, in part, from any remaining zeste activity in $z^{v 77 h}$ flies. As expected, the level and pattern of expression of $U \beta$ $\Delta-200 /-31$, U $\beta$ GAGA, and U $\beta$ NTF-1, which lack zeste protein-binding sites in the proximal promoter, are unaltered in this genetic background (Fig. 5E,F and data not shown). This genetic data provide further evidence that the zeste protein directly activates $U b x$ fusion genes in the embryo by binding the $U b x$ proximal promoter.

\section{Endogenous Ubx expression is not significantly altered in zeste mutant embryos}

The above experiments demonstrate that expression from $U b x$ promoter constructs containing zeste proteinbinding sites is strongly dependent on a functional zeste gene. However, the phenotype of $z^{v 77 h}$ flies suggests that the endogenous $U b x$ gene is properly regulated in these mutant embryos. Therefore, it was important to directly test whether zeste mutations affect the expression pattern of endogenous $U b x$. Immunohistochemical staining indicates that, as expected, there are no detectable differences in the expression of $U b x$ proteins in wild-type (Fig. 5G) and $z^{v 77 h}$ (Fig. 5H) embryos. The reason for the different effect of $z^{v 77 h}$ on $U b x$ promoter constructs versus the endogenous $U b x$ gene is presumably the result of other regulatory elements present in the $U b x$ locus, which were not included in the $\mathrm{U} \beta$ construct. Thus, the $z^{v 77 h}$ mutation may fail to affect endogenous $U b x$ because these other regulatory elements are bound by other factors that redundantly share the function of zeste.

\section{Discussion}

In this study different $U b x$ promoter constructs have been assayed in transgenic experiments to determine the role of the GAGA, NTF-1, and zeste proteins in regulating spatial patterns of transcription. All of the constructs used in these experiments include the same distant regulatory elements but contain differently mutated proximal promoters with binding sites for none, one, or all three of these proteins. Binding sites for each factor were found to activate dramatically different patterns of transcription in the epidermis. In the absence of binding sites for GAGA, NTF-1, and zeste, expression is not observed in the epidermis and is exclusively localized to the nerve cord. It is important to note that these three proteins have been purified previously to near homogeneity from embryo extracts (Biggin and Tjian 1988; Biggin et al. 1988; Dynlacht et al. 1989; M.D. Biggin, U. Heberlein, and R. Tjian, unpubl.). These experiments have demonstrated that GAGA, NTF-1, and zeste are the major, and possibly only, proteins present in these extracts that bind to the elements used in the transgenic assays. Also, each purified protein was shown to directly activate $U b x$ transcription in vitro. Thus, these biochemical experiments suggest that GAGA, NTF-1, and zeste probably act directly on the $U b x$ transgenes in the embryo. The interaction of zeste with $U b x$ transgenes has been established more thoroughly by the genetic experiments pre- sented here. These experiments show that epidermal expression from $U b x$ constructs containing zeste proteinbinding sites is strongly dependent on zeste gene function, whereas expression in the nerve cord is not. Also, expression from constructs lacking zeste proteinbinding sites is not affected in zeste mutant embryos. Therefore, the action of zeste on these transgenes is mediated by binding sites for the zeste protein.

\section{Redundant regulation of Ubx by zeste}

zeste was first shown to regulate $U b x$ by genetic experiments demonstrating that zeste is required for an intriguing process termed transvection (Lewis 1954, 1985; Kaufman et al. 1973; for review, see Wu and Goldberg 1989|. Transvection involves distant cis-regulatory elements of one $U b x$ gene copy controlling the expression of the second copy of $U b x$ in trans. This only occurs when the two gene copies are brought in close physical proximity by the pairing of homologous chromosomes. Transvection is detected only when chromosomes carrying certain combinations of mutant $U b x$ alleles are paired. It appears to be a redundant mechanism by which the distant elements regulate $U b x$, because chromosomal rearrangements that disrupt pairing of wild-type copies of the $U b x$ gene do not affect $U b x$ expression. These distant elements also control $U b x$ in cis, and this is usually regarded as the more important mechanism of regulation.

Despite the involvement of zeste in transvection, previously there has been no genetic evidence that zeste acts in the normal cis regulation of $U b x$ by the distant regulatory elements. All known mutant alleles of zeste have no detectable effect on the endogenous $U b x$ gene; this includes null mutations of zeste, as overlapping deficiencies that completely remove all zeste-coding sequences yield fertile flies that express $U b x$ normally (Goldberg et al. 1989). In contrast, our experiments not only indicate that zeste mutant embryos express $U b x$ promoter constructs at dramatically lower levels in certain tissues but also suggest that zeste mediates the cis regulation of these transgenes by the BXD distant control element. We suggest that the only probable explanation for these different observations is that the action of zeste in the cis regulation of $U b x$ is redundant. In this regard it is important to note that the $U b x$ transgenes described here include only a subset of the distant regulatory elements of $U b x$. Therefore, we assume that the other transcription factors that redundantly share the function of zeste interact with regulatory sequences not included in these transgenes.

The involvement of zeste in transvection established previously that zeste acts in a redundant pathway through which the distant elements control $U b x$. An implication of the data presented here is that the proteins proposed to redundantly share the function of zeste in cis regulation cannot substitute for the function of zeste in transvection. This would then explain why zeste mutations disrupt transvection but not the control of the endogenous $U b x$ gene in cis. 
Redundant regulation and the maintenance of gene expression

The zeste protein also binds to consensus sequences in other Drosophila promoters, including white, decapentaplegic, and zeste itself (Benson and Pirrotta 1988; Thummel 1989; Pan et al. 1991) and is detected at $>60$ loci in polytene chromosomes (Pirrotta et al. 1988). Although zeste is involved in transvection processes at white and decapentaplegic (for review, see Wu and Goldberg 1989|, the phenotype of zeste-deleted flies suggests that zeste is not essential for the activation of any of these potential target genes, except for a subtle effect on white. We propose that zeste is a strong transcriptional activator of all of these genes in vivo but that its function is redundant with that of other transcription factors. This redundancy appears to be important, as zeste has been evolutionarily conserved between highly diverged Drosophila species (Chen et al. 1992).

Another example of transcriptional redundancy may be the action of NTF-1 on Ubx. NTF-1-binding sites activate transgenic $U b x$ promoters, but mutations in the NTF-1 gene do not affect expression of endogenous $U b x$ (Bray and Kafatos 1991). Unlike zeste, the NTF-1 gene is essential and therefore cannot be redundant on all of its target genes. zeste may be unusual in this regard, as no other examples of a completely redundant transcriptional activator have been found thus far.

Redundant genes act in a number of other biological processes (Rykowski et al. 1981; Kataoka et al. 1984; Tatchell et al. 1984; Ferguson and Horvitz 1989; Elkins et al. 1990), and this redundancy may serve to stabilize these regulatory networks. This would be important in transcription if it were inherently difficult to maintain the precise level of transcription factors in a cell because of perturbations such as environmental stress or alterations in the general metabolic rate. For example, should the level of an activator transiently fall in a nonredundant system, then transcription of all target genes would also drop. If that transcription factor autoregulates its own expression positively, as zeste may, then a self-perpetuating, continuous reduction in activity would occur. This instability would not occur in a redundant system, particularly if the transcription factors also cross-regulated each other, because the network would automatically self-correct by maintaining the rate at which the genes encoding each factor are transcribed. This type of interactive network could play a key role in the maintenance of the differentiated state of eukaryotic cells.

Nonessential genes can be grouped into two classes (Ferguson and Horvitz 1989). One group comprises highly homologous members of a gene family that perform essentially the same function (Rykowski et al. 1981; Kataoka et al. 1984; Tatchell et al. 1984). Other redundant genes are not necessarily homologous and appear to be members of interacting networks of genes with only partly overlapping activities (Ferguson and Horvitz 1989; Elkins et al. 1990). Because there are no other genes in Drosophila melanogaster that show any significant homology to zeste (Chen et al. 1992) and be- cause zeste is the only protein to act on its binding site, we suggest that zeste belongs to this second class of nonessential genes.

\section{Combinatorial regulation by widely expressed transcription factors}

GAGA and zeste are expressed in most cells of the embryo, whereas NTF-1 is expressed uniformly throughout the epidermis (Pirrotta et al. 1988; Bray et al. 1989; Dynlacht et al. 1989; W. Soeller and T. Kornberg; S. Bickel and V. Pirrotta; both unpubl.). Because binding sites for these three proteins each activate different patterns of transcription in the epidermis, these proteins cannot simply act as general activators that raise the level of transcription uniformly in all cells. Instead, the factors function differently in different cells. This is presumably the result of differential interactions between GAGA, NTF-1, or zeste and spatially restricted activators and repressors. In support of this, repression of $U b x$ by the even-skipped protein appears to involve an interaction with the zeste and GAGA factors (A. TenHarmsel, R. Austin, N. Savenelli, and M.D. Biggin, unpubl.). Such combinatorial mechanisms have been shown to alter the regulatory specificity of many transcription factors and appear to be a common theme in the control of eukaryotic transcription (e.g., Herskowitz 1989; Lamb and McKnight 1991; Miner and Yamamoto 1991; Weintraub et al. 1991; Yu et al. 1991; Guarente and Bermingham-McDonogh 1992).

GAGA and zeste proteins are promoter-selective factors which, together with other widely expressed transcription factors, bind in distinct combinations to a number of different Drosophila promoters (Biggin and Tjian 1988; Soeller et al. 1988; Thummel 1989; England et al. 1990; Pan et al. 1991; Topol et al. 1991; for review, see Biggin and Tjian 1989a). Thus, the biological role of these ubiquitous factors could be to allow more complex patterns of transcription to be generated by a relatively small number of regulators, through combinatorial interactions. To date, the role of this class of regulatory proteins has not been well characterized in Drosophila, but the combined use of biochemical and genetic approaches will allow a thorough understanding of how these proteins act.

\section{Materials and methods}

Plasmid constructions

A $U b x-l a c Z$ fusion gene inserted in the Drosophila P-element vector Carnegie 20 (pU $\beta-3.1$ ) was obtained from $\mathrm{M}$. Bienz (Bienz et al. 1988). The unique $A s p 718$ site of this plasmid was destroyed by digesting with $A s p 718$, filling in, and religating. The mutant pU $\beta \Delta-200 /-31$-E contains a 150-bp MluI-SacI fragment from pUbx $\Delta 5^{\prime}-31$ (Biggin and Tjian 1988) and a 2.9$\mathrm{kb} X b a \mathrm{I}-\mathrm{NruI}$ fragment from $\mathrm{pU} \beta-3.1$ inserted into a $13-\mathrm{kb}$ $X b a \mathrm{I}-\mathrm{MluI}$ fragment from $\mathrm{pU} \beta-3.1$. This results in a unique Asp 718 site at the $\Delta-200 /-31$ junction. Plasmids $\mathrm{pU} \beta$ and pU $\beta \Delta-200 /-31$ contain a $2.2-\mathrm{kb} X b a I-N o t I$ fragment of $\mathrm{pBXD}+\mathrm{ABX}(\mathrm{X} / \mathrm{N})$ inserted into $\mathrm{XbaI} /$ NotI-digested $\mathrm{pU} \beta-3.1$ 
and $\mathrm{pU} \beta \Delta-200 /-31-\mathrm{E}$, respectively. $\mathrm{pBXD}+\mathrm{ABX}(\mathrm{X} / \mathrm{N})$ contains a 1.6-kb SacI-Asp 718 fragment of p3105VR inserted into SacI/BamHI-digested p3136SR (Müller and Bienz 1991). A NotI linker was inserted at the $A s p 718$ site of this resulting plasmid to generate $\mathrm{pBXD}+\mathrm{ABX}(\mathrm{X} / \mathrm{N})$.

The GAGA and zeste oligonucleotides used in the substitution constructs are the same as those used to construct affinity chromatography resins for the purification of these two proteins. The sequences are derived from binding sites in the $U b x$ promoter (Biggin and Tjian 1988; Biggin et al. 1988). The NTF-1 oligonucleotide used was derived from the NTF-1 binding site in the dopa-decarboxylase promoter (Dynlacht et al. 1989). This binding sequence was used instead of the binding site from the $U b x$ promoter because a zeste protein-binding site overlaps the NTF-1 site in the Ubx promoter (Biggin and Tjian 1988). The oligonucleotides used to create the binding sites are GAGA, GATCCTGGCTCTCTGTTTC and GATCGAAACAGAGAGCCAG; NTF-1, TTGAACCGGTCCTGCGGGTAC and CCGCAGGACCGGTTCAAGATC; and zeste, GATCTTTTCCACTCGTTTTTAG and GATCCTAAAAACGAGTGGAAAA. The substitution constructs pU $\beta$ GAGA, pU $\beta$ NTF-1, and pU $\beta$ ZESTE were constructed by multimerizing the respective oligonucleotides and inserting them at the Asp 718 site in $\mathrm{pU} \beta$ $\Delta-200 /-31$. The number of individual binding sites in the P-element constructs [U $\beta$ GAGA (six sites), U $\beta$ NTF-1 (five sites), U $\beta$ ZESTE (five sites)] was confirmed by DNA sequencing.

\section{Drosophila strains and transformation}

Germ-line transformation was performed essentially as de-

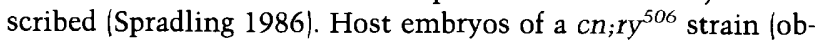
tained from B. McGinnis, Yale University, New Haven, CT) were injected with $400 \mu \mathrm{g} / \mathrm{ml}$ of the various constructs and 100 $\mu \mathrm{g} / \mathrm{ml}$ of helper $\mathrm{p} \pi 25.7 \mathrm{wc}$ (Karess and Rubin 1984). Transformants were made homozygous, and the chromosomal linkage of inserts was assessed by crosses with the balancer strains $\mathrm{CyO} ; \mathrm{ry}^{506}$ and $\mathrm{MRS} \mathrm{ry}^{2} \mathrm{Sb}$ (both obtained from M. Bienz, MRC Laboratory of Molecular Biology, Cambridge, England). $\mathrm{X}$-linked inserts were made homozygous by inbreeding. For some constructs, more transformants were obtained by crossing transformed lines to a strain containing a stable transposase source, $\Delta 2-3$ (99B) (Robertson et al. 1988; obtained from B. McGinnis). Between 5 and 10 independent transformed lines for each construct were obtained and analyzed.

To obtain homozygous $z^{v 77 h}$ embryos carrying the various $U b x$ promoter constructs, females of the zeste mutant strain (Green 1984; obtained from V. Pirrotta, Baylor College of Medicine, Houston, TX) were crossed to transgenic males carrying the transposon on one of the autosomes. Males resulting from this cross and $z^{v 77 h}$ females were mated to produce embryos for staining and analysis of expression patterns. Thus, both the maternal and zygotic contributions of the $z^{+}$gene product have been eliminated.

\section{Analysis of expression patterns}

The $l a c Z$ expression patterns have been analyzed by histochemical staining for $\beta$-galactosidase activity. Embryos were collected, dechorionated in $50 \%$ bleach, and fixed for $18 \mathrm{~min}$ in heptane saturated with $25 \%$ glutaraldehyde in PBS $(\mathrm{pH} 7.2)$. Staining was performed essentially as described (Bienz et al. 1988), except that embryos were stained before removal of their vitelline membranes by permeabilizing in PBS $+0.5 \%$ Triton $\mathrm{X}-100$ for $2 \mathrm{hr}$. Expression patterns were analyzed and photo- graphed under Nomarski optics. The embryos displayed here have been stained for different lengths of time (0.3-24 hr.).

Antibody staining with a monoclonal antibody against the Ubx proteins (White and Wilcox 1984) was performed as described (Lawrence and Johnston 1989), except that a biotinylated goat anti-mouse IgG secondary antibody (Jackson ImmunoResearch) was used with the Vectastain ABC-HRP kit (Vector Labs).

\section{Acknowledgments}

We are indebted to Jürg Müller and Mariann Bienz for describing their results and providing $U b x$ promoter constructs before publication. The view that homeotic gene expression may be maintained by a redundant, interactive network has been influenced by unpublished experiments from Mariann Bienz's laboratory. Thanks go to Mike Goldberg and Vincent Pirrotta for suggesting the $z^{v 77 h}$ allele. Fly stocks were generously provided by Mariann Bienz, Bill McGinnis, Mike Goldberg, and Vincent Pirrotta. We are grateful to Bill McGinnis and members of his laboratory for use of the injection facilities and for advice on transformation. We thank Rick Austin, Mariann Bienz, Tim Hoey, Bill McGinnis, Adam Rudner, Johannes Walter, and Trevor Williams for critically reviewing the manuscript. This work was supported by grants from the National Institutes of Health, the Searle Scholars Fund, and the Pew Charitable Trust to M.D.B.

The publication costs of this article were defrayed in part by payment of page charges. This article must therefore be hereby marked "advertisement" in accordance with 18 USC section 1734 solely to indicate this fact.

\section{References}

Beachy, P.A., S.L. Helfand, and D.S. Hogness. 1985. Segmental distribution of bithorax complex proteins during Drosophila development. Nature 313: 545-551.

Beachy, P.A., M.A. Krasnow, E.R. Gavis, and D.S. Hogness. 1988. An Ultrabithorax protein binds sequences near its own and the Antennapedia P1 promoters. Cell 55: 10691081.

Bender, W., M. Akam, F. Karch, P.A. Beachy, M. Peifer, P. Spierer, E.B. Lewis, and D.S. Hogness. 1983. Molecular genetics of the bithorax complex in Drosophila melanogaster. Science 221: 23-29.

Benson, M. and V. Pirrotta. 1988. The Drosophila zeste protein binds cooperatively to sites in many gene regulatory regions: Implications for transvection and gene regulation. $E M B O J$. 7: 3907-3915.

Bienz, M. and G. Tremml. 1988. Domain of Ultrabithorax expression in Drosophila visceral mesoderm from autoregulation and exclusion. Nature 333: 576-578.

Bienz, M., G. Saari, G. Tremml, J. Müller, B. Züst, and P.A. Lawrence. 1988. Differential regulation of Ultrabithorax in two germ layers of Drosophila. Cell 53: 567-576.

Biggin, M.D. and R. Tjian. 1988. Transcription factors that activate the Ultrabithorax promoter in developmentally staged extracts. Cell 53: 699-711.

. 1989a. Transcription factors and the control of Drosophila development. Trends Genet. 5: 377-383.

. 1989b. A purified Drosophila homeodomain protein represses transcription in vitro. Cell 58: 433-440.

Biggin, M.D., S. Bickel, M. Benson, V. Pirrotta, and R. Tjian. 1988. zeste encodes a sequence-specific transcription factor that activates the Ultrabithorax promoter in vitro. Cell 53: $713-722$ 
Bray, S.J. and F.C. Kafatos. 1991. Developmental function of Elf-1: An essential transcription factor during embryogenesis in Drosophila. Genes \& Dev. 5: 1672-1683.

Bray, S.J., B. Burke, N.H. Brown, and J. Hirsh. 1989. Embryonic expression pattern of a family of Drosophila proteins that interact with a central nervous system regulatory element. Genes \& Dev. 3: 1130-1145.

Campos-Ortega, J. and V. Hartenstein. 1985. The embryonic development of Drosophila melanogaster. Springer-Verlag, Berlin, Germany.

Castelli-Gair, J., J. Müller, and M. Bienz. 1992. Function of an Ultrabithorax minigene in imaginal cells. Development 114: 877-886.

Chen, J.D., C.S. Chan, and V. Pirrotta. 1992. Conserved DNA binding and self-association domains of the Drosophila zeste protein. Mol. Cell. Biol. 12: 598-608.

Dynlacht, B.D., L.D. Attardi, A. Admon, M. Freeman, and R. Tjian. 1989. Functional analysis of NTF-1, a developmentally regulated Drosophila transcription factor that binds neuronal cis elements. Genes \& Dev. 3: 1677-1688.

Elkins, T., K. Zinn, L. McAllister, F.M. Hoffmann, and C.S. Goodman. 1990. Genetic analysis of a Drosophila neural cell adhesion molecule: Interaction of fasciclin I and Abelson tyrosine kinase mutations. Cell 60: 565-575.

England, B.P., U. Heberlein, and R. Tjian. 1990. Purified Drosophila transcription factor, $A d h$ distal factor-1 (Adf-1), binds to sites in several Drosophila promoters and activates transcription. J. Biol. Chem. 265: 5086-5094.

Ferguson, E.L. and H.R. Horvitz. 1989. The multivulva phenotype of certain Caenorhabditis elegans mutants results from defects in two functionally redundant pathways. Genetics 123: 109-121.

Goldberg, M.L., R.A. Colvin, and A.F. Mellon. 1989. The Drosophila zeste locus is nonessential. Genetics 123: 145-155.

Green, M.M. 1984. Genetic instability in Drosophila melanogaster: Transpositions of the white gene and their role in the phenotypic expression of the zeste gene. Mol. \&) Gen. Genet. 194: 275-278.

Guarente, L. and O. Bermingham-McDonogh. 1992. Conservation and evolution of transcriptional mechanisms in eukary. otes. Trends Genet. 8: 27-32.

Herskowitz, I. 1989. A regulatory hierarchy for cell specialization in yeast. Nature 342: 749-757.

Ingham, P.W. and A. Martinez-Arias. 1986. The correct activation of Antennapedia and bithorax complex genes requires the fushi tarazu gene. Nature 324: 592-597.

Ingham, P.W. and R. Whittle. 1980. Trithorax: A new homeotic mutation of Drosophila melanogaster causing transformations of abdominal and thoracic imaginal segments. Mol. ef Gen. Genet. 179: 607-614.

Irish, V.F., A. Martinez-Arias, and M. Akam. 1989. Spatial regulation of the Antennapedia and Ultrabithorax homeotic genes during Drosophila early development. EMBO $J$. 8: $1527-1537$.

Irvine, K.D., S.L. Helfand, and D.S. Hogness. 1991. The large upstream control region of the Drosophila homeotic gene Ultrabithorax. Development 111: 407-424.

Johnson, P.F. and S.L. McKnight. 1989. Eukaryotic transcriptional regulatory proteins. Annu. Rev. Biochem. 58: 799839.

Karess, R.E. and G.M. Rubin. 1984. Analysis of P transposable element functions in Drosophila. Cell 38: 135-146.

Kataoka, T., S. Powers, C. McGill, O. Fasano, J. Strathern, J. Broach, and M. Wigler. 1984. Genetic analysis of yeast Ras1 and Ras2 genes. Cell 37: 437-445.

Kaufman, T.C., S.E. Tasaka, and D.T. Suzuki. 1973. The inter- action of two complex loci, zeste and bithorax in Drosophila melanogaster. Genetics 75: 299-321.

Krasnow, M.A., E.E. Saffman, K. Kornfeld, and D.S. Hogness. 1989. Transcriptional activation and repression by Ultrabithorax proteins in cultured Drosophila cells. Cell 57: 1031-1043.

Lamb, P. and S.L. McKnight. 1991. Diversity and specificity in transcriptional regulation: The benefits of heterotypic dimerization. Trends Biochem. Sci. 16: 417-422.

Lawrence, P.A. and P. Johnston. 1989. Pattern formation in the Drosophila embryo: Allocation of cells to parasegments by even-skipped and fushi tarazu. Development 105: 761-767.

Lewis, E.B. 1954. The theory and application of a new method of detecting chromosomal rearrangements in Drosophila melanogaster. Am. Nat. 88: 225-239.

- 1978. A gene complex controlling segmentation in Drosophila. Nature 276: 565-570.

- 1985. Regulation of genes of the bithorax complex in Drosophila. Cold Spring Harbor Symp. Quant. Biol. 50: 155-164.

Mansukhani, A., P.H. Gunaratne, P.W. Sherwood, B.J. Sneath, and M.L. Goldberg. 1988. Nucleotide sequence and structural analysis of the zeste locus of Drosophila melanogaster. Mol. \&) Gen. Genet. 211: 121-128.

Martinez-Arias, A. and R.A.H. White. 1988. Ultrabithorax and engrailed expression in Drosophila embryos mutant for segmentation genes of the pair-rule class. Development 102: 325-338.

Miner, J.N. and K.R. Yamamoto. 1991. Regulatory crosstalk at composite response elements. Trends Biochem. Sci. 16: 423-426.

Mitchell, P.J. and R. Tjian. 1989. Transcriptional regulation in mammalian cells by sequence-specific DNA binding proteins. Science 245: 371-378.

Müller, J. and M. Bienz. 1991. Long range repression conferring boundaries of Ultrabithorax expression in the Drosophila embryo. EMBO J. 10: 3147-3155.

Müller, J., F. Thüringer, M. Biggin, B. Züst, and M. Bienz. 1989. Coordinate action of a proximal homeoprotein binding site and a distal sequence confers the Ultrabithorax expression pattern in the visceral mesoderm. EMBO $/$. 8: 4143-4151.

Pan, D., J.-D. Huang, and A.J. Courey. 1991. Functional analysis of the Drosophila twist promoter reveals a dorsal-binding ventral activator region. Genes \& Dev. 5: 1892-1901.

Pirrotta, V., E. Manet, E. Hardon, S.E. Bickel, and M. Benson. 1987. Structure and sequence of the Drosophila zeste gene. EMBO /. 6: 791-799.

Pirrotta, V., S. Bickel, and C. Mariani. 1988. Developmental expression of the Drosophila zeste gene and localization of zeste protein on polytene chromosomes. Genes \& Dev. 2: 1839-1850.

Qian, S., M. Capovilla, and V. Pirrotta. 1991. The $b x$ region enhancer, a distant cis-control element of the Drosophila $U b x$ gene and its regulation by hunchback and other segmentation genes. EMBO /. 10: 1415-1425.

Robertson, H.M., C.R. Preston, R.W. Phillis, D.M. JohnsonSchlitz, W.K. Benz, and W.R. Engels. 1988. A stable genomic source of $\mathrm{P}$ element transposase in Drosophila melanogaster. Genetics 118: 461-470.

Rykowski, M.C., J.W. Wallis, J. Choe, and M. Grunstein. 1981. Histone H2B subtypes are dispensable during the yeast cell cycle. Cell 25: 477-487.

Simon, J., M. Peifer, W. Bender, and M. O'Connor. 1990. Regulatory elements of the bithorax complex that control expression along the anterior-posterior axis. EMBO J. 9: 39453956. 
Soeller, W.C., S.J. Poole, and T. Kornberg. 1988. In vitro transcription of the Drosophila engrailed gene. Genes \& Dev. 2: $68-81$.

Spradling, A.C. 1986. P element-mediated transformation. In Drosophila: A practical approach (ed. D.B. Roberts), pp. 175197. IRL Press, Washington, D.C.

Struhl, G. and M. Akam. 1985. Altered distributions of Ultrabithorax transcripts in extra sex combs mutant embryos of Drosophila. EMBO J. 4: 3259-3264.

Struhl, G. and R.A.H. White. 1985. Regulation of the Ultrabithorax gene of Drosophila by other bithorax complex genes. Cell 43: 507-519.

Tatchell, K., D.T. Chaleff, D. DeFeo-Jones, and E.M. Scolnick. 1984. Requirement of either of a pair of ras-related genes of Saccharomyces cerevisiae for spore viability. Nature 309: 523-527.

Thummel, C.S. 1989. The Drosophila E74 promoter contains essential sequences downstream from the start site of transcription. Genes \& Dev. 3: 782-792.

Topol, J., C.R. Dearolf, K. Prakash, and C.S. Parker. 1991. Synthetic oligonucleotides recreate Drosophila fushi tarazu zebra-stripe expression. Genes \& Dev. 5: 855-867.

Weintraub, H., R. Davis, S. Tapscott, M. Thayer, M. Krause, R. Benezra, T.K. Blackwell, D. Turner, R. Rupp, S. Hollenberg, Y. Zhuang, and A. Lassar. 1991. The myoD gene family: Nodal point during specification of the muscle cell lineage. Science 251: 761-766.

White, R.A.H. and R. Lehmann. 1986. A gap gene, hunchback, regulates the spatial expression of Ultrabithorax. Cell 47: 311-321.

White, R.A.H. and M. Wilcox. 1984. Protein products of the bithorax complex in Drosophila. Cell 39: 163-171.

1985. Regulation and distribution of Ultrabithorax proteins in Drosophila. Nature 318: 563-567.

Winslow, G.M., S. Hayashi, M. Krasnow, D.S. Hogness, and M.P. Scott. 1989. Transcriptional activation by the Antennapedia and fushi tarazu proteins in cultured Drosophila cells. Cell 57: 1017-1030.

Wu, C.-T. and M.L. Goldberg. 1989. The Drosophila zeste gene and transvection. Trends Genet. 5: 189-194.

Yu, V.C., C. Delsert, B. Andersen, J.M. Holloway, O.V. Devary, A.M. Näär, S.Y. Kim, J.-M. Boutin, C.K. Glass, and M.G. Rosenfeld. 1991. RXR $\beta$ : A coregulator that enhances binding of retinoic acid, thyroid hormone, and vitamin $D$ receptors to their cognate response elements. Cell 67: 1251-1266.

Zhang, C.-C., J. Müller, M. Hoch, H. Jäckle, and M. Bienz. 1991. Target sequences for hunchback in a control region conferring Ultrabithorax expression boundaries. Development 113: 1171-1179.

Zink, B. and R. Paro. 1989. In vivo binding pattern of a transregulator of homeotic genes in Drosophila melanogaster. Nature 337: 468-471. 


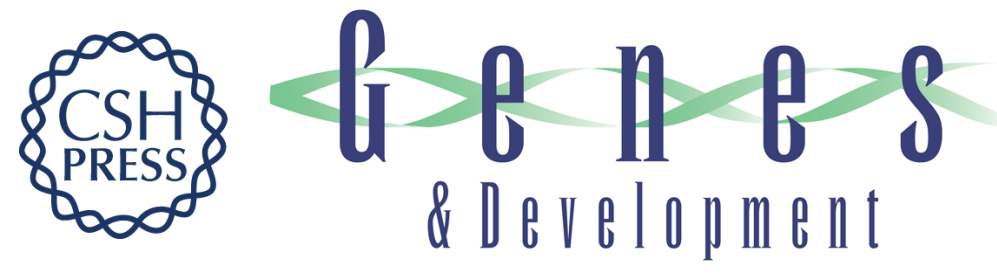

\section{zeste, a nonessential gene, potently activates Ultrabithorax transcription in the Drosophila embryo.}

J D Laney and M D Biggin

Genes Dev. 1992, 6:

Access the most recent version at doi:10.1101/gad.6.8.1531

References This article cites 64 articles, 23 of which can be accessed free at: http://genesdev.cshlp.org/content/6/8/1531.full.html\#ref-list-1

License

Email Alerting

Service

Receive free email alerts when new articles cite this article - sign up in the box at the top right corner of the article or click here.

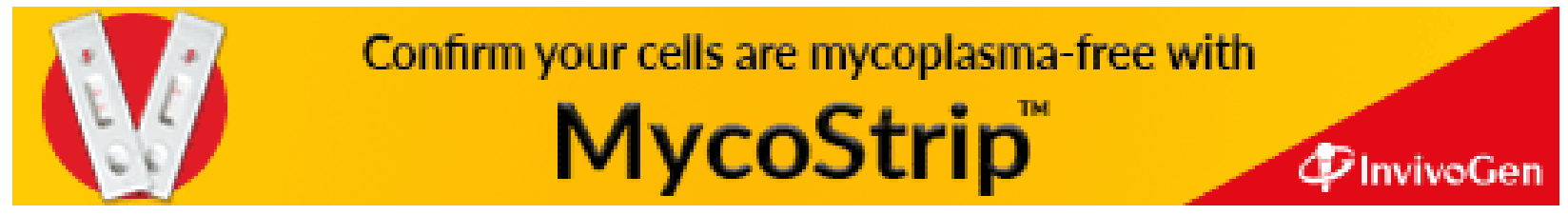

